\title{
Modelos de Gestão por Competências: Um estudo longitudinal em uma empresa automobilística
}

\author{
Janete Knapik ${ }^{1, *}$, Bruno Henrique Rocha Fernandes², \\ Synara Sepúlveda Sales ${ }^{3}$
}

\begin{abstract}
http://orcid.org/0000-0002-3449-1376 / Universidade Positivo, Brasil; Universidade Federal de Santa Catarina (UFSC), Brasil
2 http://orcid.org/0000-0003-4437-5720 / Pontifícia Universidade Católica do Paraná (PUCPR), Brasil; Fundação Dom Cabral (FDC), Brasil

${ }^{3}$ http://orcid.org/0000-0002-7792-4952 / Universidade Tuiuti do Paraná (UTP), Brasil
\end{abstract}

Os Modelos de Gestão por Competência (MGC) são concebidos para alinhar as práticas de gestão de pessoas entre si, integrados à estratégia organizacional. Entretanto, tais modelos podem diferir significativamente entre si, conforme incorporam ou não elementos estratégicos, como as competências organizacionais. O respectivo estudo de caso analisou tais questões na implantação e revisões subsequentes de um MGC em uma multinacional do setor automobilístico. A metodologia investigativa utilizou estudo qualitativo, analisando os diferentes momentos dessa implantação em uma análise longitudinal, utilizando, à pesquisa, um recorte temporal de dez anos - de 1999 a 2019. Os dados foram coletados por meio de entrevistas semi-estruturadas, observação participante, bem como de análise documental. Observou-se que: o uso de referenciais estratégicos como competências organizacionais propicia a integração vertical entre processos de gestão de pessoas à estratégia; os conceitos de competências individuais influenciaram a amplitude e a aplicabilidade do MGC. Foi possível perceber que os processos organizacionais favorecem uma maior ou menor assimilação do MGC. O tempo dedicado na implementação foi importante para denotar seus efeitos. Palavras-chave: gestão de pessoas, competências profissionais, estratégias.

\section{Competence management models: A longitudinal study in an auto company}

\section{Abstract}

Competency management models (CMMs) are designed to align people management practices with each other and with the organizational strategy. However, such models can differ significantly from each other, depending on whether or not they incorporate strategic elements, such as organizational skills. This case study analyzed such issues in the implantation and subsequent revisions of a CMM in a multinational automobile firm. The methodology consisted of a qualitative study, analyzing the different moments of this implantation in a longitudinal analysis from 1999 to 2019. Data was collected through semi-structured interviews, participant observation, and document analysis. It was observed that the use of strategic references as organizational competencies provides vertical integration between people management processes and strategy; the concepts of individual competences influenced the breadth and applicability of the CMM; organizational processes favor greater or lesser assimilation of the CMM; and that the time spent on implementation was important.

Keywords: personnel management, professional competence, strategies.

\section{Modelos de Gestión de Competencias: Un estudio longitudinal en una empresa automotriz}

\section{Resumen}

Los Modelos de Gestión por Competencias (MGC) son concebidos para alinear las prácticas de gestión de personas entre sí, insertados a la estrategia organizacional. Sin embargo, tales modelos pueden diferir significativamente entre sí, dependiendo de si incorporan o no elementos estratégicos, como las habilidades de organización. Este estudio de caso analizó tales problemas en la implantación y las revisiones posteriores de un MGC en una empresa multinacional del sector del automovilístico. La metodología investigativa utilizó del estudio cualitativo, analizando los diferentes momentos de esta implementación en un análisis longitudinal, utilizando, a la pesquisa, un recorte temporal de diez años - de 1999 a 2019. Los datos fueron recolectados a través de entrevistas semiestructuradas, bien como de análisis documental. Se observó que: el uso de referencias estratégicas como competencias organizacionales proporciona una integración vertical entre los procesos de gestión de personas en la estrategia; los conceptos de competencias individuales influyeron en la amplitud y aplicabilidad del MGC. Fue posible percibir que los procesos organizacionales favorecen una mayor o menor asimilación del MGC. El tiempo dedicado a la implementación fue importante para denotar sus efectos.

Palabras-clave: administración de personal, competencia profesional, estrategias. 
O tema gestão estratégica de gestão de pessoas vem ganhando relevância tanto para a prática como na pesquisa organizacional e ao menos dois atributos caracterizam este tipo de gestão, a integração vertical e a integração horizontal. A integração vertical busca o alinhamento das práticas de gestão de pessoas com os objetivos e estratégias da empresa e a integração horizontal refere-se à atuação coordenada das diversas atividades práticas de gestão de recursos humanos (Audenaert, Vanderstraeten, Buyens, \& Desmidt, 2014). Nesse contexto, Modelos de Gestão por Competência (MGC) consistem num modo particular de operacionalizar a gestão estratégica de pessoas, à medida que utilizam um referencial, as competências, como elemento para proporcionar tanto a integração vertical com a estratégia como a integração horizontal, entre as práticas de gestão de pessoas, preparando a organização para os resultados que pretende alcançar, para as demandas do ambiente corporativo e não apenas nos processos e eficiência de seus subsistemas (Wright \& McMahan, 1992).

Os MGC têm respaldo na Visão Baseada em Recursos (VBR), proposta por Barney (1991), que considera o ambiente interno da organização como um conjunto de recursos a serem articulados em prol das estratégias organizacionais. A VBR oferece um substrato teórico adotado por diversos estudiosos em seus campos de estudo sobre estratégias: se os recursos internos forem bem articulados, surgem possibilidades de ganhos e consequente aumento dos lucros para a organização (Dalfovo, Machado, Gonçalves, \& Baumgartner, 2017). Partindo desse pressuposto, estratégias bem-sucedidas consistem na combinação e exploração adequada de recursos, únicos, difíceis de imitar e substituir e ao mesmo tempo passíveis de transferência interna dentro do próprio negócio. À medida que as organizações combinam tais recursos criam vantagem competitiva e geram valor superior (Mário, Silva \& Vasconcelos, 2016). A vantagem competitiva é efetivada por meio de recursos valiosos que capacitam a empresa a desenvolver suas atividades com um desempenho superior em comparação com a concorrência, a fim de que sejam fatores determinantes de vantagem competitiva (Junges \& Dal-Soto, 2017).

\section{Competências Organizacionais e Individuais}

Na área organizacional, o conceito de competências é abordado sob diversos níveis, o organizacional e o individual (Fernandes, 2013). A noção de competências organizacionais deriva diretamente da VBR e consiste na articulação de recursos de forma a propiciar um desempenho particular na organização. Quando em nível de destaque, tais competências são denominadas de Core Competence ou Competências Essenciais, e consistem na viabilização e integração de tecnologias e habilidades no processo produtivo, são difíceis de serem imitadas e viabilizam competitividade organizacional; permitem interagir e transformar recursos em produtos e serviços, garantindo uma vantagem competitiva (Prahalad \& Hamel, 1990). Um segundo nível do uso competência na área organizacional inclui as competências profissionais. Um precursor no uso deste conceito foi McClelland (1973), que recomendou o uso de competências como uma alternativa às avaliações de inteligência em processos seletivos. Para McClelland (1973), competências constituem características subjacente da pessoa relacionada com um desempenho superior em uma tarefa ou em uma determinada situação.

Dutra (2004) distingue diferentes correntes conceituais de competências profissionais em uma linha do tempo. Entre os anos 70 e 90 para alguns autores, a maioria americanos, competência é um conjunto de qualificações (conhecimentos, habilidades e atitudes) que uma pessoa possui para executar um trabalho dentro de um nível superior de qualidade, sendo os principais defensores desta corrente McClelland (1973), Boyatzis (1982), e Spencer e Spencer (1993). Nos anos 80 e 90 estas concepções foram contestadas por muitos autores, a maioria europeus como Le Boterf (1995), Zarifian (1996) e Elliot (1990). Para estes autores, o fato das pessoas possuírem as qualificações não garante que entreguem o que lhes é demandado. Neste contexto, a competência só existe quando está em ação, o que pressupõe um saber ser e saber mobilizar conhecimentos em diversos contextos. Estas correntes convergem para uma terceira abordagem, para uma junção destas duas correntes, em que a competência é a somatória da ação e das qualificações (Dutra, 2004; McLagan, 1980).

Dutra (2004), ao abordar a competência em ação, introduziu o conceito de "entrega", isto é, "tudo aquilo que o indivíduo se predispõe a oferecer à organização relativo ao seu trabalho; ou seja, seu modo de atuar, sua maneira de realizar o trabalho solicitado e suas realizações" (Dutra, 2004, p.28). Nessa abordagem conceitual o fato de uma pessoa possuir um conjunto de conhecimentos, habilidades e atitudes não garante que a organização se beneficiará diretamente, ou seja, as competências devem ser um conjunto de capacidades (conhecimentos, habilidades e atitudes) necessárias para a que a pessoa exerça seu trabalho e atue como agente de transformação destas capacidades em competência entregue para a organização e agregar valor efetivo ao patrimônio de conhecimentos da organização (Dutra, 2016).

Nos processos de gestão de pessoas, o conceito de competência profissional passa a dar ênfase aos resultados do trabalho humano e a impor mudanças profundas em estrutura, sistemas, políticas e práticas das organizações. As políticas de recursos humanos deixam de ser passivamente integradas às estratégias de negócios e passam a ser parte integrante dessa estratégia (Ubeda, Santos, \& Nagano, 2017). Nesse sentido, as competências profissionais tem um enfoque bilateral, devem agregar valor econômico para a empresa e valor social para os indivíduos, é "um saber agir responsável e reconhecido, que implica mobilizar, integrar, transferir conhecimentos, recursos, habilidades que agreguem valor econômico à organização e valor social ao indivíduo" (Fleury \& Fleury, 2004, p.30).

Os conceitos de competência organizacional e individual, embora distintos, se articulam dentro das organizações. Fernandes et al. (2006) argumentam que as competências organizacionais são constituídas de recursos, sendo a competência profissional o mais importante, não só porque é um recurso mobilizado pela organização, mas sobretudo porque é uma instância geradora e articuladora dos demais recursos. Recursos individuais, se desarticulados, não conseguem sustentar uma vantagem competitiva, mas quando entrelaçados e coordenados é que se tornam valiosos, difíceis de imitar ou substituir (Carstens, Vincenzi, Fernandes, \& Galvão, 2016), sendo tal coordenação exercida por meio de competências profissionais, considerando a complexidade do ambiente em que a organização se encontra e outras demandas sociais. Dutra (2004) também destaca a interação entre competências organizacionais e individuais. Para o autor, organizações e pessoas demonstram uma contínua troca de experiências: as organizações desenvolvem as pessoas, não apenas para a empresa, mas para a sociedade, e as pessoas desenvolvem suas capacidades, transferindo para a organização seu aprendizado, enriquecendo o patrimônio de conhecimentos organizacional. Desta reciprocidade há crescimento nas competências profissionais e organizacionais. Anos mais tarde, Dutra (2016) arremata a ideia da interação entre competências profissionais e organizacionais, ao afirmar que o desenvolvimento do conceito de competências ocorre por meio de um processo dinâmico no qual de um lado encontra-se a organização e seu conjunto próprio de competências, construídas a partir de um processo de aprendizagem organizacional e que são concretizadas em seu patrimônio de conhecimentos, de 
outro lado têm-se as pessoas, com seu conjunto de competências que pode ou não ser aproveitado pela empresa (Dutra, 2016).

\section{Modelos de Gestão por Competências}

As ideias acima expostas embasam a proposição dos chamados Modelos de Gestão por Competências (MGC). Tais modelos representam tentativas organizacionais de organizar e alinhar suas práticas de gestão de pessoas entre si e com as estratégias organizacionais, tendo por base o conceito de competências (Audenaert et al., 2014). O MGC é um sistema de gestão que identifica competências relevantes à estratégia organizacional e as articula aos processos de gestão de pessoas, como recrutamento e seleção, treinamento e desenvolvimento, gestão de performance, carreira e sucessão, remuneração, de modo a fomentar o desenvolvimento dos indivíduos e da organização (Lima, Zambroni-de-Souza, \& Araújo, 2015). Por meio de MGC, a organização consegue alinhar os seus objetivos estratégicos com o desenvolvimento dos seus funcionários e consequentemente tende incrementar seus resultados (Piza, 2017).

Os Modelos de Gestão por Competências fomentam a integração vertical com a estratégia e interagem com a gestão de conhecimentos na organização (Li, Clark, \& Sillince, 2018; Sisson \& Ryan, 2016), mapeiam competências e conhecimentos críticos para a construção de estratégias e a criação de competências essenciais e de vantagens competitivas para a organização. Por meio de MGC, o conhecimento tácito é codificado, articulado e difundido como conhecimento explícito corporativo, que posteriormente é incorporado à base de conhecimento tácito e utilizado para construir sentido (sensemaking) e criar conhecimentos individuais (Li et al., 2018). Um MGC mapeia competências profissionais como sendo um desdobramento das competências organizacionais, desta forma, o MGC deve ser implementado orientado pelas estratégias e competências organizacionais, seguido do mapeamento das competências profissionais. Tais competências profissionais devem nortear todos os processos de gestão de pessoas e garantir o alinhamento estratégico da área de recursos humanos (Ceribelli, Tamashiro, Botelho \& Fernandes, 2019). Outro fator importante na gestão por competências é a necessidade de alinhar a área de recursos humanos com os gerentes de linha e a organização, sem negligenciar questões culturais e processos como a utilização de tecnologias da informação e o domínio do conhecimento dos processos de gestão de recursos humanos e das competências para a atuação como parceiro estratégico (Botter, Rosa, \& Lima, 2018).

A transição de um modelo de gestão de pessoas tradicional para um MGC articula mudanças na organização em três níveis: na importância dada às pessoas relacionando as ao sucesso das estratégias de negócio; nas políticas adotadas para atração, retenção e desenvolvimento de competências necessárias para o negócio da empresa e nas formações das competências (Fleury \& Fleury, 2004). O modelo deve traduzir estes objetivos estratégicos e organizacionais, em requisitos necessários essenciais às pessoas em quaisquer funções específicas e deve abordar todos os processos envolvidos na produção, implementação e desenvolvimento de competências. A adoção de uma abordagem baseada em competências para a gestão de recursos humanos permite que estas competências sejam eliciadas, descritas e avaliadas (Silva, Ribeiro, Alvarez, \& Caregnato, 2019). Ainda, MGCs, por serem pautados numa filosofia de desenvolvimento mútuo entre indivíduo e organização, procuram distribuir o poder horizontalmente, promovem o conceito de empoderamento, delegam e cobram poder ao mesmo tempo, exigem mais criatividade e competências de relacionamento (Martins, Tinôco, Vieira, \& Rodrigues, 2015).

MGCs, assim como o conceito de competências, sofreram ajustes e mudanças com o tempo, podem ser classificados como: modelos baseados em capacidades, modelos baseados em entregas e modelos que integram capacidades e entregas (Fernandes, 2013). MGCs baseado em capacidades têm como referência os autores da primeira geração dos conceitos de competências, como Spencer e Spencer (1993), que definem competências como qualificações subjacentes de um indivíduo, e Boyatzis (1982) que explica a competência como uma característica ou uma habilidade que a pessoa possui e que lhe confere a possibilidade de demonstrar determinadas ações específicas apropriadas. MGCs baseado em entregas se baseiam em os autores da segunda geração dos conceitos de competências (Le Boterf, 1995; Zarifian, 2001). Nesse modelo, a competência não se configura apenas como um conhecimento, um saber ou uma habilidade, mas como "tomar iniciativa e assumir responsabilidade individual diante de situações profissionais com as quais uma pessoa se depara" (Zarifian, 2001, p. 68). Neste modelo, o foco das competências sai das qualificações prescritas pelo cargo e considera o indivíduo e a compreensão das demandas que mobilizam seu repertório de capacidades que se traduzem em entregas adequadas (Dutra, 2016). Por fim, os MGCs que integram estratégias e entrega entendem competências em suas duas dimensões, as capacidades (conhecimentos, habilidades e atitudes) e a respectiva entrega (Dutra, 2004; Fleury \& Fleury, 2004). Esta geração distingue entrega de resultado, a entrega está ligada à capacidade de contribuição e é mais duradouro enquanto o resultado é mensurável e com data para que seja alcançado (Dutra, 2016).

Um MGC pretende articular instrumentos e práticas de gestão de pessoas e formar um elo de contribuição singular à implementação das estratégias, porém o conceito de competência (e o consequente MGC) adotado pode ampliar ou restringir tal possibilidade. Um estudo realizado por Fernandes e Comini (2008) junto a 67 empresas brasileiras, líderes ou referências em seus segmentos e que adotaram um MGC, identificou diferenças expressivas nos conceitos de competências adotados, bem como variedade no uso em que tais empresas faziam do conceito de competências para orientar suas práticas de gestão de pessoas. Ainda, outro dado levantado pelos autores revelou que, independente do segmento e da estratégia da organização, havia grande similaridade nos nomes e mesmo nas descrições das competências adotadas por tais organizações, o que demonstra uma frouxidão conceitual e a similaridade nas competências adotadas em MGCs de organizações diversas indicavam uma subutilização de tais modelos, à medida que as competências não traduziam especificidade de suas estratégias e sequer permitiam realizar a integração vertical e horizontal entre estratégia e práticas de gestão de pessoas. Em seguida, os autores lançam cinco proposições para justificar porquê MGC têm sido subutilizados ou são similares, independente das estratégias e do segmento empresarial: 1) o conceito de competências organizacionais não é trabalhado adequadamente; 2) as organizações não dispensam tempo suficiente para o processo de estruturação do MGC; 3) as organizações contentam-se com "modelos de prateleiras", já prontos, propostos por consultorias ou copiados de outras empresas; 4) são enfatizados modelos de competências gerenciais, sem enfatizar especificidades técnicas de processos essenciais e 5) ocorre uma institucionalização dos MGC sem o respaldo conceitual adequado.

As conclusões geradas desse levantamento de Fernandes e Comini (2008) sobre modelos de competência inspiraram este estudo, que busca analisar em uma situação real, de uma empresa automotiva, como ocorreu a construção e implementação do Modelo de Gestão por Competências (MGC) ao longo de 20 anos, de 1999 a 2019. Analisa-se em que medida as proposições de Fernandes e Comini (2008) se fizeram presentes e, em particular, como diferentes conceitos de competências orientaram MGCs diversos, com diferentes implicações para práticas de 
gestão de pessoas e para contribuição às estratégias da empresa.

A relevância desta pesquisa para os Estudos Organizacionais e para a Psicologia do Trabalho e das Organizações está nas suas contribuições teóricas e práticas, ao articular um conceito central na psicologia do trabalho, competências, às suas implicações, orientado por revisão da literatura e procedimentos metodológicos para verificar tais noções em um contexto empírico, e com recomendações para a prática, abrangendo o alinhamento da gestão de pessoas. Para tanto, após revisão dos principais conceitos que embasam a pesquisa, (competências organizacionais, competências profissionais e modelos de competências), apresenta-se a metodologia da abordagem empírica na próxima seção. A esta se segue a apresentação dos resultados, onde se descreve as diversas fases na implantação das competências na organização em estudo. Finaliza-se com as conclusões, aonde se investiga em que medida a trajetória da empresa na implantação do MGC corrobora as proposições de Fernandes e Comini (2008) e as implicações conceituais e práticas da pesquisa.

\section{Método}

A estratégia de investigação adotada é o estudo de caso descritivo e explanatório Yin (2016). Descritivo, porque descreve as fases da implantação do modelo de gestão por competências (implementação do MGC e revisões) com informações sobre os motivos da adoção dos MGC, o processo adotado e resultados percebidos e explanatório por buscar compreender as causas que levaram a empresa a adotar um MGC e suas revisões e implicações, utilizando as proposições de Fernandes e Comini (2008) e conceitos de competências como base. A perspectiva temporal é um comparativo de momentos no mesmo caso, em uma análise longitudinal, de 1999 a 2019. A empresa em estudo pertence ao segmento automotivo; implantou um modelo de gestão por competência no ano de 1999 e realizou três revisões posteriores, em 2003, 2007 e 2010, respectivamente, permanecendo esta última sem grandes alterações até a conclusão desta pesquisa em 2019. O estudo avalia a configuração do MGC a partir de uma adaptação das proposições de Fernandes e Comini (2008) e conceitos de competências, assumindo-os como elementos influenciadores da construção do modelo (Figura 1). De forma mais específica, avaliou-se: 1. a adoção do conceito de competências organizacionais ou outro referencial estratégico como balizador do MGC; 2. o conceito de competência profissional que embasou o MGC; 3. o contexto e processos envolvidos na implantação; 4. o tempo dedicado à construção. A proposição relativa à institucionalização não foi verificada, pois envolveria comparação com outras organizações, a fim de identificar a similaridade entre competências e suas razões, algo fora do escopo deste trabalho.

\section{Participantes}

A pesquisa foi realizada em uma empresa multinacional do segmento automotivo de Curitiba, líder em seu segmento. Foram quatro participantes, sendo identificados com letras gregas, Alfa; Beta; Gama e Delta. O entrevistado Alfa foi consultor, ajudou na compreensão e comunicação do momento D em 2009; o entrevistado Beta foi gerente de recursos humanos por 15 anos na empresa, de 1994 a 2009, aposentando-se nesse ano; o entrevistado Gama é um especialista em RH da empresa participante e acompanhou a implantação em todos os momentos, o entrevistado Delta é consultor que atuou diretamente na revisão do modelo no momento B em 2003.

\section{Instrumentos}

Os dados foram coletados por meio de entrevistas semiestruturadas em profundidade seguindo um roteiro com 32 perguntas, observação participante e análise documental e bibliográfica. Todas as estratégias tinham o objetivo de investigar as especificidades da construção do MGC e as proposições de Fernandes e Comini (2008). Após a primeira entrevista, o roteiro de perguntas foi adaptado para cada entrevistado de acordo com a participação na construção do modelo. A observação participante ocorreu durante a segunda revisão em 2010, em que dois dos autores acompanharam o processo ao longo reuniões semanais na empresa. $\mathrm{Na}$ análise de documentos foram resgatadas e analisadas propostas de consultorias e materiais entregues como relatório de conclusão, slides, folders, material de comunicação, entre outros documentos produzidos na implementação em 1999 e na primeira revisão em 2003.

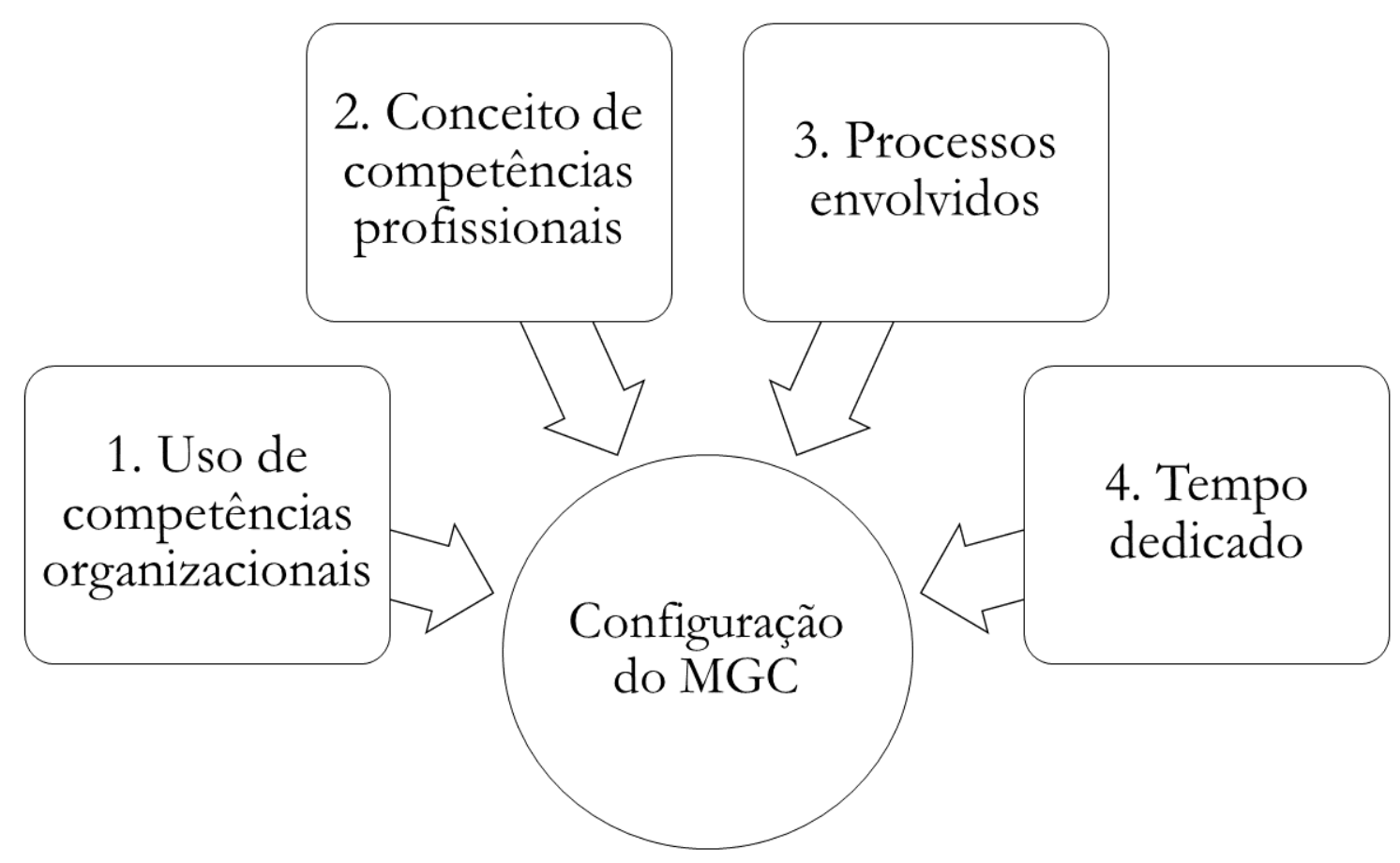




\section{Procedimento de Coleta de Dados e Cuidados Éticos}

Os dados coletados referem-se a cinco momentos distintos, considerando a implementação em 1999, as revisões de 2003, 2007 e 2010 e a confirmação do modelo atual em 2019. Os cortes de investigação de implementação e revisões foram denominados como Momento A - Implementação em 1999; Momento B - Primeira revisão em 2003; Momento C - Segunda revisão em 2007 e Momento D - Terceira revisão em 2010; no Momento $\mathrm{E}$ foi verificado se houve a continuidade do modelo (Figura 2). as inferências e suposições adequadas dos momentos A, B, C e D. A quarta etapa foi a avaliação do estágio do MGC em 2019, junto ao participante Gama, que acompanhou o modelo desde 1999. Por fim, a quinta etapa consistiu na redação das conclusões da análise dos dados. Todos os procedimentos éticos foram adotados, os participantes foram convidados de forma voluntária e informados sobre os benefícios, riscos e isenção de custo. Foi respeitada a privacidade e a confidencialidade dos resultados e das informações obtidas em todas as etapas do projeto, tendo sido solicitada autorização para a escrita e publicação do artigo. Optou-se pela mudança de nomes dos participantes para preservar sua identidade.
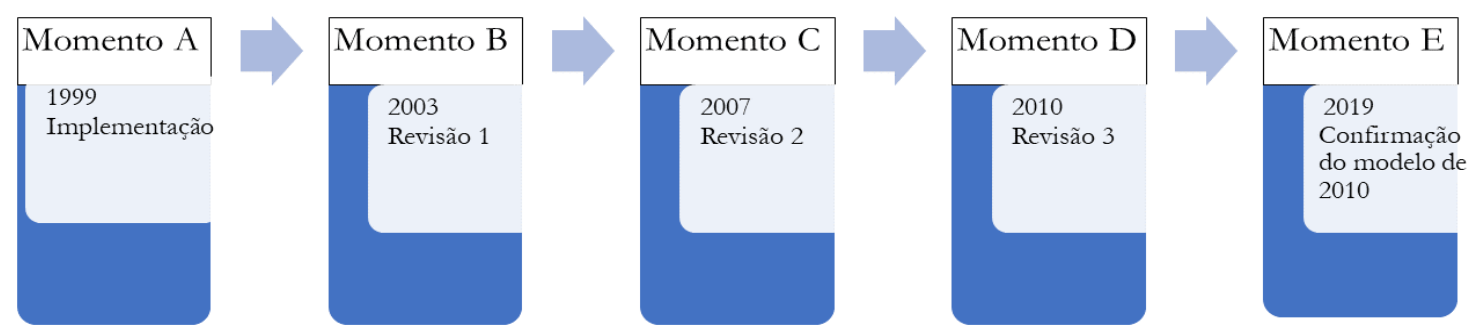

Figura 2. Cortes de investigação dos Modelos de Gestão por Competências. Nota: Desenvolvido pelos autores.

Na primeira etapa da coleta de dados, em 2010, uma das pesquisadoras iniciou os estudos como observadora participante de um grupo de trabalho durante 10 meses, acompanhando as reuniões da segunda revisão do MGC. A segunda etapa foi a realização de entrevistas semiestruturadas em profundidade com os responsáveis diretos pela decisão, modelagem e implementação do MGC e suas sucessivas revisões. Concomitantemente, realizou-se a análise de documentos (propostas, relatórios, material de comunicação etc.) e bibliográfica (artigos publicados). A terceira etapa compreendeu a análise do caso a partir das categorias escolhidas,

\section{Procedimento de Análise de Dados}

A análise dos dados deu-se pela verificação dos conceitos de competências norteadores da construção e implantação dos MGCs, em cada momento. Também foram analisados os processos envolvidos na construção do MGC por meio dos documentos disponibilizados, das entrevistas e da leitura de textos publicados anteriormente sobre o MGC da empresa estudada. Para evitar subjetividades, adotou-se o emprego de Definições Constitutivas (DC) e Definições Operacionais (DO), um dos critérios para jul-

Tabela 1

Definições Constitutivas e Operacionais das categorias analiticas de pesquisa

\begin{tabular}{cc} 
Modelos & Definições \\
\hline D.C.: Modelo integrador de instrumentos de gestão de pessoas e um elo de contribuição singular à implementação das estratégias
\end{tabular}

Modelo de Gestão por Compe-_ (Fernandes e Comini, 2008).

tências (MGC)

D.O.: Avaliado mediante amostra de documentos, analisando as descrições das competências nos diversos períodos e o uso destas competências nos processos de RH (Recrutamento e Seleção, Treinamento e Desenvolvimento, Remuneração, Avaliação de Desempenho etc.). A análise documental foi complementada por entrevistas

D.C.: Conjunto de recursos coordenados que geram valor à organização, são difíceis de imitar, podem ser transferidos para outras áreas, produtos ou serviços da organização, e impactam o desempenho organizacional em um fator chave ao seu sucesso (Fernandes, Fleury, \& Mills, 2006, p.32)

Competências organizacionais D.O.: Identificado mediante amostra de documentos. Observado se a empresa define formalmente alguma competência organizacional, seja direta e explicitamente ou mediante algum tipo de formalização que remeta à ideia de competência organizacional tal qual nomeada neste trabalho, e em que medida isto foi utilizado para definir competências individuais

D.C.: Um saber agir responsável e reconhecido, que implica mobilizar, integrar, transferir conhecimentos, recursos, habilidades que agreguem valor econômico à organização e valor social ao indivíduo (Fleury \& Fleury 2004, p.30)

D.O.: Foi identificado mediante análise de documentos e entrevistas. Em primeiro foram identificadas e analisadas as competências escolhidas em cada fase do modelo. Em segundo, buscou-se identificar dois fatores durante a construção do MGC:

Competências profissionais $\quad$ 1) se as competências individuais foram construídas para dar suporte às competências organizacionais;

2) qual o critério de escolha das competências individuais.

- Se há uma formalização;

- Quais as competências que foram definidas;

Embasamento conceitual destas definições: CHA (conhecimentos, habilidades e atitudes), Entrega, ou ambas. Natureza das competências (Técnicas e Gerenciais)

D.C.: Metodologias ou instrumentos utilizados para viabilizar a implantação, por exemplo: grupos envolvidos, materiais de divulgação. Abrange a amplitude dos processos envolvidos na construção e sustentação do MGC.

Processos envolvidos D.O.: Identificado mediante entrevista com profissionais envolvidos nas respectivas construções dos modelos (implementação e revisões) e análise de documentos. Busca-se averiguar se foram incluídos processos técnicos críticos na eleição das competências individuais.

D.C.: De acordo com Senge (1999), o tempo das pessoas é consumido por muitas tarefas e metas impostas pela gerência e acabam tendo pouco tempo disponível para se dedicar ao que poderia ser mais importante e estratégico à empresa. A questão do tempo exige que profissionais-chave dispendam horas suficientes para iniciativas bem-sucedidas, horas estas que envolvam: reflexão, planejamento, trabalho colaborativo e treinamento.

D.O.: Foi identificado mediante entrevistas com profissionais envolvidos nas respectivas construções dos modelos (implementação e revisões) e análise de documentos. O estudo busca identificar as pessoas que foram designadas para a construção do MGC e investigar quem são estas pessoas, têm uma posição estratégica, o papel das consultorias envolvidas e quanto e como foi o tempo dedicado para a estruturação do MGC. 
gar a qualidade da pesquisa consiste em escrever definições conceituais e operacionais dos principais categorias do estudo para que se saiba exatamente o que se pretende estudar (Yin, 2016), demonstrados na Tabela 1. A Definição Constitutiva (DC) traduz o significado de um termo ou expressão e a Definição Operacional (DO) além do significado ajuda por meio de exemplos a compreensão do conceito, trazendo clareza ao conceito (Marconi \& Lakatos, 1991). Além das categorias de pesquisa, registrou-se, para cada momento, o motivo alegado para implantação, as dificuldades e resultados relatados. A análise do conteúdo foi realizada por meio do registro síntese das respostas dos entrevistados em um quadro analítico, Tabela 4 , de modo a comparar e analisar as especificidades dos MGCs em cada momento.

\section{Resultados e Discussão}

A empresa implementou um Modelo de Gestão por Competências em 1999, sendo pioneira na adoção deste modelo de gestão em Curitiba e entre as empresas do grupo em nível mundial. Em 2003, realizou a primeira revisão do modelo, e outras duas revisões ocorreram sucessivamente em 2007 e 2010, esta última permanecendo até 2019 sem grandes alterações. A empresa já foi considerada como a melhor empresa para se trabalhar no ranking das revistas Exame - Você S/A, da editora Abril e conquistou o Prêmio Nacional da Qualidade (PNQ) nos anos de 2009, 2012 e 2015.

\section{Contextos e Motivações da Implementação e Revisões dos MGC's na Empresa}

No Momento A, em 1999, a decisão pela implementação do MGC se deu em função de grandes mudanças na orientação estratégica da empresa. O MGC foi considerado, entre outros processos de gestão, um catalizador de mudanças radicais na empresa. A decisão pela consultoria deu-se devido a representatividade de obras publicadas que a recomendavam. Foram desenhadas competências específicas para os cargos, demonstrado com um exemplo de descrição na Tabela 2. Para cada competência, seja genérica ou específica, existiam níveis de proficiência (N1, N2, N3 e N4, Tabela 3).

Tabela 2

Exemplo de Competência Genérica do MGC de 1999

\section{Definição}

É a capacidade para alcançar resultados positivos para a organização em termos de rentabilidade, produtividade, qualidade, investimentos e outros

aspectos não financeiros, adaptando-se rapidamente às mudanças de qualquer natureza e/ou situação de pressão no trabalho.

Nota: Desenvolvido pelos autores.

No Momento A do MGC, a ênfase foi dada aos sistemas de remuneração e as definições das competências estavam embasadas na primeira geração de conceitos, que considera a competência como um conjunto de conhecimentos, habilidades e atitudes que um profissional poderia ter para ser considerado competente, ou seja, nos inputs (Boyatzis, 1982; McClelland, 1973; Spencer \& Spencer, 1993). A motivação para o Momento B, primeira revisão em 2003, deu-se porque o antigo modelo apresentava algumas dificuldades práticas, principalmente com grandes demandas de Treinamento e Desenvolvimento e progressão salarial. Não existia uma uniformidade nas definições das competências e nas escalas de avaliação, o que multiplicava o número de critérios e cargos; faltava a integração entre as práticas e subsistemas de RH, a ênfase do modelo era para remuneração; o modelo comportava uma mistura de aspectos de naturezas diferentes em uma mesma dimensão de avaliação; as faixas salariais eram largas e com critérios de avaliação que nem sempre explicavam a contribuição do
Tabela 3

Niveis de Proficiência do MGC de 1999

\begin{tabular}{cc}
\hline Nível & Definição \\
\hline N1- & $\begin{array}{c}\text { Competência sendo aprimorada, desenvolvida. O de- } \\
\text { sempenho das atividades requer o acompanhamento de } \\
\text { profissionais mais experientes, sendo capaz de solu- } \\
\text { cionar questões mais simples da atividade/processo. O } \\
\text { desempenho das atividades requer o acompanhamento de } \\
\text { profissionais mais experientes, sendo capaz de solucionar } \\
\text { questões mais simples da atividade/processo. }\end{array}$ \\
\hline N2 - Aplicação & $\begin{array}{c}\text { Competência sendo aplicada. Sua utilização se focaliza na } \\
\text { realização das atividades/processo dentro dos padrões } \\
\text { de qualidade e desempenho estabelecidos (KPI'S), sendo } \\
\text { capaz de solucionar questões de solucionar questões de } \\
\text { média complexidade da atividade/processo. }\end{array}$ \\
\hline Competência sendo usada de forma otimizada. Sua utili- \\
zação se focaliza no aperfeiçoamento das atividades/pro- \\
cesso superando os padrões esperados de desempenho \\
(KPI'S), sendo capaz de solucionar questões complexas \\
da atividade/processo.
\end{tabular}

Nota. Desenvolvido pelos autores.

profissional à empresa; o sistema não tinha clareza e simplicidade que facilitasse o entendimento do processo de desenvolvimento e a trajetória profissional dos empregados; os horizontes de desenvolvimento não eram percebidos como factíveis; os sistemas de avaliação estavam desalinhados. Com o objetivo de suprir estes gaps do momento A, a revisão do MGC no momento B adotou um modelo mais integrativo e que contemplasse também a prática das competências; a base conceitual de competências desta revisão alinhava-se à terceira geração dos conceitos de competência, que a considera como um conjunto de capacidades (inputs) acompanhado da entrega (outputs), ou seja, a noção de competência em ação. Ocorreu a introdução no MGC de eixos de carreira, níveis de complexidade e espaço ocupacional. O modelo trouxe clareza e objetividade nos critérios de avaliação, definições distintas entre as capacidades exigidas (inputs) e a agregação de valor ou entregas (outputs). Também possibilitou integrar as práticas de RH como recrutamento e seleção; carreira, avaliação; desenvolvimento e remuneração. O sistema de remuneração passou a ter critérios bem definidos e atrelados ao nível de complexidade. Os programas de desenvolvimento estavam alinhados com esse nível de complexidade e os requisitos necessários para um determinado espaço ocupacional (Le Boterf, 1995; Zarifian, 1996; Elliot Jacques, 1990) e também o conceito de entrega ou outputs (Dutra, 2004).

Na revisão de 2007, Momento C, a iniciativa partiu da gerência de RH que pretendia usar as competências como instrumento para avaliar os ativos intangíveis da organização e, ao mesmo tempo, trabalhar competências mais específicas por processos de negócio. Assim identificou-se a importância de inserir a noção de competências organizacionais. O projeto foi conduzido por dois grupos, um seguido ao outro em anos sucessivos, que participaram de duas edições diferentes de um programa de MBA in company realizado na empresa. O primeiro passo foi a revisão das competências organizacionais por meio da análise do negócio e dos fatores críticos de sucesso da empresa e a comparação com as competências inseridas nos cargos. Na sequência as competências profissionais foram analisadas e comparadas com as competências organizacionais, com o objetivo de identificar se a relação era forte, média ou fraca, visando analisar a integração entre as competências da organização e das pessoas. Esta revisão foi uma complementação do MGC anterior, inserindo no modelo o conceito de competências organizacionais e incluiu a articulação de uma relação causal 


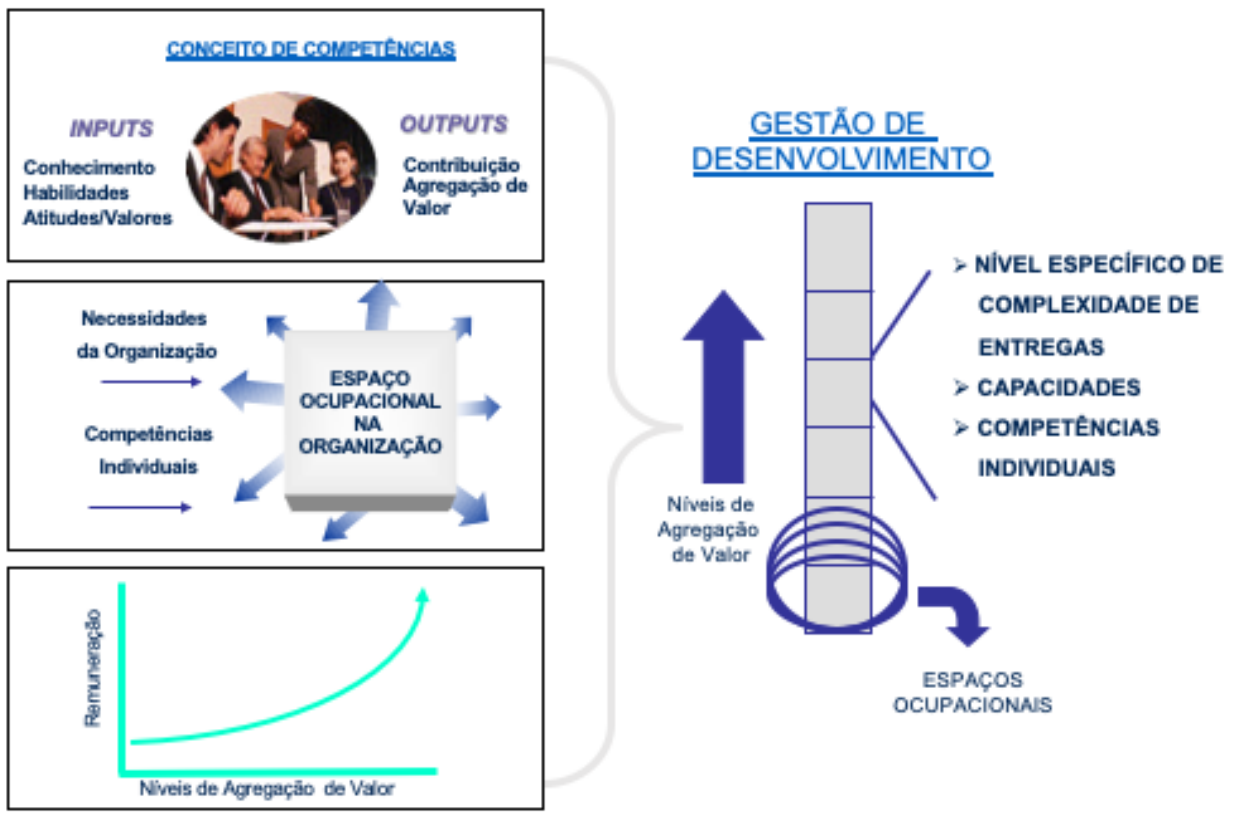

Figura 3. Modelo do MGC em 2003. Nota: material utilizado pela empresa. Utilizado com autorização da empresa.

entre competências profissionais, competências organizacionais e estratégias (Fernandes \& Comini, 2008; Fernandes et al., 2006).

Na revisão de 2010, Momento D, a empresa recebeu um modelo já pronto da matriz, que foi construído por um grupo de profissionais de diferentes países e modelado para ser gerido por todas as fábricas a nível mundial. Esta versão do MGC faz uma junção do modelo de Leadership Pipeline, de Charan, Drotter e Noel (2017) com as competências da consultoria americana Lominger International (Lombardo \& Eichinger, 2005). O modelo do Leadership Pipeline enfatiza o processo de desenvolvimento gerencial, comparando-o a um pipeline, tubulação usada para o transporte de fluidos a grandes distâncias. O modelo faz uma relação entre o aumento do nível de complexidade dos desafios e as necessidades de abstração demandados de um profissional ao longo de sua carreira e propõe seis passagens numa carreira de gestão, com novas demandas na função de liderança, e em cada ponto é necessário efetuar uma transformação com novas capacidades e papéis. $\mathrm{O}$ modelo de Pipeline busca desenvolver as pessoas, distribui tarefas que exigem mais ao longo do tempo e permite que as pessoas aprendam e pratiquem as habilidades necessárias, permanece o conceito de níveis de complexidade e de espaço ocupacional. Por outro lado, as "competências" da Lominger pautam-se mais pelo conceito de competências da primeira geração, traduzindo mais habilidades e atitudes. Analisando-as sob o conceito da terceira geração (competências como capacidades mobilizadas para uma entrega), ficariam melhor enquadradas como "capacidades". Nenhum membro da filial brasileira participou da construção do modelo mundial do Momento D, apenas se envolveu para sua implantação no país.

A Tabela 4 apresenta uma síntese das informações coletadas que permitiram a análise dos resultados e atender os objetivos desta pesquisa. $\mathrm{Na}$ coleta das informações obtidas nas entrevistas, os respondentes identificaram pontos críticos nos modelos. Consideraram que no momento A ocorreram problemas conceituais e que o modelo era muito complexo e difícil de ser comunicado aos empregados. No momento B, faltou a compreensão do conceito de competências organizacionais e uma relação com as competências da matriz, que foram inseridas ao longo do processo. Assim, coexistiam duas ferramentas de avaliação, uma desenvolvida localmente e outra vinda da matriz, e assim um excesso de competências, o que dificultava ações focadas na avaliação e desenvolvimento. No momento C, os entrevistados perceberam que o tempo de discussões foi muito prolongado e que os participantes tinham pouco engajamento estratégico, fato que difi- cultou a assimilação do modelo. O momento $\mathrm{D}$, foi gerenciado pela matriz sem envolvimento da subsidiária local na concepção do modelo; esta apenas o recebeu e teve que disseminá-lo.

Os aspectos positivos mais evidentes dos MGCs também foram destacados pelos entrevistados. No momento B os pontos bem avaliados foram a noção de entrega, níveis de complexidade e eixos de carreira, conceitos que ajudaram na integração dos processos de gestão de pessoas. Além disso, o processo fomentou a conscientização da importância dos resultados; da profissionalização dos empregados e a preocupação por realizar a integração vertical e horizontal da gestão de pessoas com estratégias da empresa. No momento $\mathrm{C}$ o ponto positivo destacado foi a inserção de competências organizacionais e, no momento D, a assertividade do modelo. Os aspectos negativos mais evidentes nos MGCs, foram: no momento A, a ausência dos níveis de complexidade; no momento B o excesso de competências e a sobreposição com a chegada de competências da matriz. No momento C, a falta de foco no processo de modelagem e de patrocínio, e no momento $\mathrm{D}$, a ênfase só nas lideranças. O MGC do momento D se mantém há cerca de 10 anos. A persistência do modelo traduz a consistência no uso das práticas da empresa, com vistas à sua assimilação, e de prover com o modelo um parâmetro para a gestão de pessoas caso contrário, um modelo volátil não criaria referenciais. Revela, também, a consistência estratégica da organização e a valorização de alinhar aspectos culturais, coletivos e globais da empresa.

\section{Conclusão}

O presente estudo visou analisar aspectos importantes na implantação de um MGC, a saber, o quanto este modelo está integrado à estratégia organizacional (integração vertical); o quanto o conceito de competências influencia a amplitude, assimilação e uso do MGC pela organização; o quanto processos de construção e sustentação contribuem para o uso do MGC; e o quanto o tempo dedicado pela organização é condição necessária para a implantação e assimilação. Tais aspectos, foram avaliados em uma multinacional do setor automotivo que, desde 1999, vem trabalhando com MGC, tendo realizado revisões no modelo ao longo do tempo, com diferentes inspirações conceituais e processos envolvidos. A trajetória na implantação do MGC na organização revelou a mudança das bases conceituais do modelo e, pelas análises, tais mudanças permitiram um maior alcance e aplicabilidade ao longo do tempo. O MGC do Momento A prescindiu de maior preocu- 
Tabela 4

Quadro analítico dos resultados da pesquisa

\begin{tabular}{|c|c|c|c|c|}
\hline $\begin{array}{l}\text { Cortes da } \\
\text { pesquisa }\end{array}$ & $\begin{array}{c}1999 \\
\text { Momento A }\end{array}$ & $\begin{array}{c}2003 \\
\text { Momento B }\end{array}$ & $\begin{array}{l}2007 \\
\text { Momento C }\end{array}$ & $\begin{array}{c}2010 \\
\text { Momento D }\end{array}$ \\
\hline Motivo & $\begin{array}{l}\text { Mudança organizacional Estruturação do } \\
\text { sistema de remuneração Organização da } \\
\text { Empresa }\end{array}$ & $\begin{array}{l}\text { Integração de práticas de RH Desenho de crité- } \\
\text { rios de complexidade. Redução do budget do RH } \\
\text { (Vinculação com resultados e entrega) }\end{array}$ & $\begin{array}{l}\text { Complementação do modelo } \\
\text { anterior inserindo o conceito } \\
\text { de competências organiza- } \\
\text { cionais }\end{array}$ & $\begin{array}{l}\text { Imposição } \\
\text { da matriz. } \\
\text { Decisão por } \\
\text { uma unifor- } \\
\text { mização a } \\
\text { nível mundial }\end{array}$ \\
\hline $\begin{array}{l}1 . \\
\text { Competências } \\
\text { organizacionais } \\
\text { e estratégias }\end{array}$ & $\begin{array}{l}\text { As mudanças estratégicas induziram decisão } \\
\text { por um MGC mas não foram contempladas } \\
\text { na modelagem. Sem vinculação com compe- } \\
\text { tências organizacionais. }\end{array}$ & $\begin{array}{l}\text { Sem explicitação das competências organizacio- } \\
\text { nais e estratégias. }\end{array}$ & $\begin{array}{l}\text { Consideração das compe- } \\
\text { tências organizacionais e das } \\
\text { estratégias na modelagem. }\end{array}$ & $\begin{array}{l}\text { Sem explici- } \\
\text { tação diretas } \\
\text { das compe- } \\
\text { tências orga- } \\
\text { nizacionais e } \\
\text { estratégias. }\end{array}$ \\
\hline $\begin{array}{l}2 . \\
\text { Competências } \\
\text { individuais } \\
\text { (natureza das } \\
\text { competências } \\
\text { e conceitos } \\
\text { envolvidos) }\end{array}$ & $\mathrm{CHA}$ & $\begin{array}{l}\text { Capacidades + Entrega Modelo integrador de } \\
\text { práticas de RH. Eixos de carreira. Níveis de } \\
\text { complexidade. }\end{array}$ & $\begin{array}{l}\text { Competências organizacionais } \\
\text { Capacidades + entregas. Mo- } \\
\text { delo integrador de práticas de } \\
\text { RH. Eixos de carreira. Níveis } \\
\text { de complexidade. Mapeamen- } \\
\text { to de recursos Intangíveis. }\end{array}$ & $\begin{array}{l}\text { Leadership } \\
\text { Pipeline \& } \\
\text { Lominger }\end{array}$ \\
\hline
\end{tabular}

Construção coletiva na modelagem. Pessoas chaves da empresa foram escolhidas para modelagem, (um representante dos empregados) e à medida que as discussões avançam, cada membro sensibilizava suas áreas de atuação. Sensibilização por meio de comunicação

3. Processos envolvidos visual (cartilhas, folders e um dicionário de competências e workshops) O Modelo foi implementado ao mesmo tempo em toda empresa. Monitorado como um projeto, com suas fases e mudanças. A consultoria trouxe o "saber" e participou da concepção, sendo a aplicação responsabilidade do RH
Tempo de modelagem e aplicação mais rápida. Existia uma cultura de competências. Construção coletiva na modelagem Pessoas chaves da empresa foram escolhidas para modelagem, inclusive um representante dos empregados e à medida que as discussões avançam, cada membro já ia sensibilizando suas áreas. Comunicação visual intensa por meio da intranet e duas palestras mensais abertas a todos os empregados até o final do modelo. Existia dois modelos de competências, uma segunda lista de competências veio da matriz, as duas avaliações eram feitas separadamente, sem vínculo. A consultoria contribui com o "saber" e participou da concepção, sendo a aplicação responsabilidade do RH.

\begin{tabular}{lll}
\hline $\begin{array}{l}\text { 4. Tempo } \\
\text { dedicado }\end{array}$ & Cerca de 150 horas & Cerca de 153 horas \\
\hline
\end{tabular}

Mudanças radicais; Falta de adesão da alta di-

Dificuldades reção; Falta de um piloto Natureza conceitual; Critérios subjetivos para avaliação
Complexidade do modelo que induzia réguas diferentes de avaliação. Não aceitação da representação dos empregados. Permitia percepção de que todos os empregados chegariam ao topo. Falta de adesão da alta.
Não foi implementado Caráter acadêmico Construção coletiva na modelagem, mas com profissionais com pouca influência estratégica. Um grupo de profissionais que participaram de um MBA in company de desenvolvimento de lideranças, optou por realizar a revisão no TCC Aprofundamento das competências técnicas
Desenvolvido a nível mundial. A filial brasileira não teve um representante na modelagem.

Sem informações

Recebimento do modelo pronto, sem adaptação

Falta de patrocínio de pessoas à realidade de um nível estratégico. Falta da filial de foco na modelagem. A brasileira. sinalização do modelo D Possível falta abortou a revisão do mo- de integração mento C. com outras ferramentas de avaliação e desempenho.

Confusão conceitual. Modelo complexo tanto na concepção quando nos sistemas de apoio. Remuneração: a aquisição de habilidade habilita e gera expectativa de progressão salarial. Muita demanda para as áreas de T\&D e progressão salarial. Participação ativa dos membros nos grupos de modelagens. A empresa conseguiu resultados organizacio-

Resultados obtidos nais e as mudanças esperadas, inclusive na satisfação dos resultados. (Além do MGC, outros projetos foram implementados. Inseriu a cultura de competência na empresa. Critérios confusos para avaliação. Um programa piloto poderia ter corrigido falhas da construção do modelo. Resistências internas. Faltou entender o modelo antes de implementar. O primeiro nível hierárquico não incorporou e não "dava exemplos”. Redução das reclamações sindicais.

Tempo de modelagem e aplicação mais rápida. Há existência de uma cultura de competências facilitou o processo. A comunicação foi mais intensa e facilitada pela intranet. Percepção da relevância dos Resultados corporativos. Resistência dos empregados pois preferiam ser avaliados por tempo "de casa". Modelo complexo, difícil de passar para os empregados. Falta de alinhamento com as competências propostas pela matriz. Induziu nos empregados a uma crença de que todos chegariam ao topo da carreira. O primeiro nível hierárquico não incorporou e não "dava exemplos". As pessoas das áreas aderiram pouco na construção do modelo porque demandava muito tempo. Muitas competências. Os empregados não gostavam de avaliar e ser avaliados duas vezes. Aumento do profissionalismo e da empregabilidade.
Foi parcialmente implementado. Caráter acadêmico. Dificuldade para pensar em competências organizacionais quando existem várias unidades de negócio bem diferentes, por exemplo: TI, construção, comercial etc. Discussões sem foco e prolongadas.

Confusão conceitual do termo competências. Assertividade Especificidades (passo a passo) Divisão da empresa por níveis de complexidade 
pação com a estratégia; as competências foram pensadas, naquele momento, mais como elemento integrador das práticas de gestão de pessoas. Além disso, o conceito de competência profissional adotado, com ênfase nas capacidades, sem menção à entrega, e sem incorporar o conceito de níveis de complexidade, revelou-se de difícil operacionalização, por ter gerado uma "corrida para qualificação" (atrelada a movimentações salariais) e não ter uma avaliação mais assertiva se a competência resultava numa entrega. Algumas limitações motivaram a revisão no Momento B, que visou realizar uma maior integração do MGC à estratégia. Para tanto, incorporou um conceito de competências de terceira geração, com definição de capacidades e entregas, níveis de complexidade e eixos de carreira. O movimento permitiu uma melhor integração das competências para balizar os diversos processos de gestão de pessoas. Entretanto, o modelo foi percebido como complexo, algo que se agravou com a introdução, pela matriz, de novas competências profissionais para balizar avaliações e ações de desenvolvimento

Tanto os Momentos A e B usufruíram de forte patrocínio organizacional, o que não aconteceu no Momento C. Este foi iniciativa localizada da área de gestão de pessoas que mobilizou grupos interdisciplinares de alunos de MBA da companhia, que desenharam competências organizacionais e competências técnicas. O trabalho aparentou consistência, mas não foi implantado, seja pela ausência de patrocínio, seja porque, ao seu final, já se sinalizava um novo modelo "pronto" da matriz. O Momento D correspondeu à chegada do modelo da matriz e sua implantação na subsidiária local, tinha ênfase em competências de lideranças e os conceitos que o embasavam estavam alinhados a noções já instaladas nos MGCs anteriores. O modelo alcançou mais as posições de liderança, o que permitiu sua coexistência com as competências anteriores para avaliar e gerir os quadros técnicos da empresa. Este último MGC vem se revelando efetivo e assimilado na organização, dado sua permanência por mais de dez anos.

Voltando-se às proposições que embasaram o estudo, observou-se: 1. o uso de referenciais derivados da estratégia, e particularmente o conceito de competências organizacionais, revelou-se importante elo integrador para dar envergadura estratégica ao MGC. 2. o conceito de competências utilizado influenciou a amplitude e aplicabilidade do modelo. Quando utilizado o MGC baseados em conceitos de primeira geração, a organização teve dificuldade de implementação e gestão, por força de implicações derivadas do modelo. A partir da adoção de conceitos de terceira geração, a integração entre práticas foi facilitada, bem como a compreensão do modelo por parte dos funcionários. Quanto à proposição 3, os processos envolvidos revelaram-se essenciais à implantação do processo. Nos momentos em que estiveram presentes com maior intensidade, o modelo foi adotado; quando faltaram processos mais robustos de apoio à implantação, as iniciativas não se efetivaram. A última proposição 4 , relativa ao tempo dedicado, não constituiu um problema, nem elemento diferenciador na assimilação do MGC em nenhum dos momentos. Em todos os casos, a organização disponibilizou tempo para estudo, trabalho e engajamento das pessoas em prol da implantação do MGC. Assim, por não se constituir num elemento diferenciador entre os quatro momentos, não se pode concluir sobre a efetividade ou não desta categoria na implantação de um MGC.

No seu conjunto, o estudo evidencia a importância de referenciais estratégicos, como competência organizacional, e a adoção de conceitos de competências profissionais pertinentes para a implantação de um MGC, além de processos de construção e sustentação adequados, corroborando as proposições que motivaram o estudo. Se presentes, tais elementos viabilizam a integração vertical e horizontal de um MGC. Destaca- ainda, a necessidade da persistência estratégica da organização para a institucionalização de uma prática organizacional. No caso em questão, observa-se uma trajetória de mais de vinte anos, com esforço de melhoria contínua de uma prática. Este estudo avaliou a implantação de MGC por competências a partir de um estudo de caso único, observando-se alguns aspectos importantes à sua implantação.

Novos estudos poderiam examinar esta questão observando-se casos múltiplos. Ainda por resolver está a questão da efetividade de tais modelos, estudos indicam sua pertinência em contextos específicos e para variáveis particulares (Sanı, Yozgat \& Çakarel, 2016; Rocha, Passador, \& Shinyashiki, 2017). O presente estudo pouco avança neste sentido, para o qual novas pesquisas se fazem necessárias.

\section{Referências}

Audenaert, M., Vanderstraeten, A., Buyens, D., \& Desmidt, S. (2014). Does alignment elicit competency-based HRM? A systematic review. Management Revue, 25(1), 5-26.

Barney, J. B. (1991). Firms resources and sustained competitive advantage. Journal of Management, 17(1), 99-120. https://doi.org/10.1177/014920639101700 108

Boyatzis, R. E. (1982). The competence manager: A model for effective performance ( $\left.1^{\mathrm{a}} \mathrm{ed}.\right)$. New York: John Wiley \& Sons

Botter, J., Rosa, D. G., \& Lima, L. C. (2018). The Differences Between the Model and Competencies of the Strategic Partnership Between Human Resource Management and Line Managers in National and Multinational Companies. Review of International Business, 13(3), 28-41. Recuperado de https://papers. ssrn.com $/$ sol3 $/$ papers.cfm?abstract id $=3264069$

Carstens, D. D. D. S., Vincenzi, T. B. D., Fernandes, B. H. R., \& Galvão, F. F. (2016). Tecnogran: todo piso será palco. Toda parede, mural. E a cidade inteira, poesia. Read. Revista Eletrônica de Administração, 22(3), 519-537. https://doi.org/10.1590/1413-2311.16815.60638

Ceribelli, H. B., Tamashiro, H. R. S., Botelho, A. A., \& Fernandes, J. S. (2019). Gestão por competências: Um estudo de caso em uma indústria de bebidas do Brasil. Revista Nucleus, 16(1).

Charan, R., Drotter, S., \& Noel, J. (2017). Pipeline de liderança: o desenvolvimento de lideres como diferencial competitivo. Rio de Janeiro: Sextante

Dalfovo, M. S., Machado, M. M., Gonçalves, A., \& Baumgartner, A. (2017). Visão baseada em recursos e monitoramento do ambiente e sua influência nas capacidades dinâmicas. Intelig. Compet., 7(2), 133-178. Recuperado de http://www.inteligenciacompetitivarev.com.br/ojs/index.php/rev/article/ view $/ 221 /$ pdf 106

Dutra, J. S. (2004). Competências: conceitos e instrumentos para gestão de pessoas na empresa moderna (2a ed.). São Paulo: Gente.

Dutra, J. S. (2016). Gestão de Pessoas - Modelo, Processos, Tendências e Perspectivas (2ª ed). São Paulo: Atlas

Elliott, J. (1990). In Praise of Hierarchy. Harvard Business Review.

Fernandes, B. H. R., Fleury, M. T. L., \& Mills, J. (2006). Construindo o diálogo entre competência, recursos e desempenho organizacional. Revista de Administração de Empresas, 46(4), 1-18. https://doi.org/10.1590/S003475902006000400006

Fernandes, B. H. R., \& Comini, G. (2008). Limitações na Estruturação de Modelos de Gestão por Competências: uma Análise de Organizações Lideres em Diversos Setores. XXXII Encontro da ANPAD.

Fernandes, B. H. R. (2013). Gestão Estratégica de Pessoas com Foco em Competência (1 ed.). Rio de Janeiro: Elsevier

Fleury, A., \& Fleury, M. T. (2004). Estratégias empresariais e formação de competências: um quebra cabeça caleidoscópio da indústria brasileira ( $3^{\mathrm{a}}$ ed.). São Paulo: Atlas.

Junges, V.C., \& Dal-Soto, F. (2017). Recursos e capacidades estratégicas como fontes de vantagem competitiva no clube arranca. Revista Capital CientificoEletrônica (RCCe) 15(1), 43-59. https://doi.org/ 177-4153.20170003

Le Boterf, G. (1995). De la compétence - essai sur un attracteur étrange. In: Les éditions d'organisations. Paris: Quatrième Tirage.

Lima, C. M. P., Zambroni-de-Souza, P. C., \& Araújo, A. J. S. (2015). A Gestão do Trabalho e os Desafios da Competência: uma Contribuição de Philippe Zarifian. Psicologia: Ciência e Profissão, 35(4), 1223-1238. https://doi. org/10.1590/1982-3703001972013

Li, S., Clark, T., \& Sillince, J. (2018) Constructing a strategy on the creation of core competencies for African companies. Technological Forecasting and Social Change, 131, 204-213. https://doi.org/10.1016/j.techfore.2017.08.008

Lombardo, M. M., \& Eichinger, R. W. (2005). Fyi for your improvement ${ }^{\mathrm{TM}}$ 4th Edition: A guide for development and coaching for: Learners, Managers, Mentors, and Feedback. Givers. Minneapolis: Lominger Limited.

Marconi, M. A., \& Lakatos, E. M. (1991). Fundamentos de metodologia científica (3.ed.). São Paulo: Atlas 
Mário, F. A., Silva, F. M., \& Vasconcelos, R. C. R. (2016). Gestão estratégica de competências organizacionais: conceitos, critérios e recursos. Revista Eletrônica de Administração, 15(1),- 4-16. Recuperado de http://periodicos. unifacef.com.br/index.php/rea/article/view/1000/936

Martins, I., Tinôco, D. S., Vieira, J. X., Rodrigues, T. L. (2015). Gestão de pessoas por competências: da construção epistemológica a sua referência como padrão de recursos humanos no setor público brasileiro. Rev. CCEIURCAMP, 19(34), 63-74. Recuperado de http://revista.urcamp.tche.br/ index.php/Revista CCEI/article/view/37

McClelland, D. (1973). Testing for Competence Rather Than for Intelligence. American Psychologist.

McLagan, P. A. (1980). Competency models. Training and Development Journal, $34(2), 22-26$

Piza, D. H. T. (2017). Gestão de pessoas por competência na era do conhecimento. Revista Gestão em Foco, 9.

Prahalad, C. K., \& Hamel, G. (1990). The core competence of the corporation. Harvard Business Review, 68(3), 79-91, 969-987.

Rocha, G. B., Passador, C. S., \& Shinyashiki, G. T. (2017). What is the social gain from competency management? The employees' perception at a Brazilian public university. Revista de Administração, 52(3), 233-245. https://doi. org/10.1016/j.rausp.2017.05.001.

Sani, F. O. Ü., Yozgat, U., Çakarel, T. Y. (2016). How Employees' Perceptions of Competency Models Affect Job Satisfaction? Mediating Effect of Social Exchange. Academy of Strategic Management Journal, 15(2), 36-46.

Senge, P. M. (1999). A Dança das Mudanças: os desafios de manter o crescimento e o sucesso em organizaçoes que aprendem $\left(7^{\mathrm{a}} \mathrm{ed}\right)$. Rio de Janeiro: Campus

Silva, V. M., Ribeiro, J. L. D., Alvarez, G. R., \& Caregnato, S. E. (2019). Competence-Based Management Research in the Web of Science and Scopus Databases: Scientific Production, Collaboration, and Impact. Publications, 7(4), 1-21. https://doi.org/10.3390/publications 7040060

Sisson, P. W., \& Ryan, J. (2016). Indications of a Justifiable Unified Competency Theory of Knowledge Management. Proceedings of the European Conference on Knowledge Management, 1080-1089.

Spencer L. M., \& Spencer, S. (1993). Competence at work (1 $\left.1^{\mathrm{a}} \mathrm{ed}.\right)$. New York: John Wiley \& Sons.

Ubeda, C. L., Santos, F. C. A., \& Nagano, M. S. (2017). Análise das contribuições das competências individuais para a gestão da inovação com base na triangulação de métodos de pesquisa. Gestão \& Produção, 24(3), 595-609. https://doi.org/10.1590/0104-530x1481-16

Wright, P. M., \& McMahan, G. C. (1992). Theoretical perspectives for strategic human resource management. Journal of Management, 18(2), 295-320. https://doi.org/10.1177/014920639201800205

Yin, R. K. (2016). Pesquisa qualitativa do início ao fim (2 $2^{\mathrm{a}}$ ed). Nova York: The Guilford Press.

Zarifian, P. (1996). A gestão da e pela competência. Rio de Janeiro: Centro Internacional para Educação, Trabalho e Transferência de Tecnologia.

Zarifian, P. (2001). Objetivo competência: por uma nova lógica (1ª ed.). São Paulo: Atlas.

\section{Informações sobre os autores:}

\section{Janete Knapik}

Rua Gastão Câmara, 540, apto. 1204 T, Bigorrilho, Curitiba (PR), Brasil, CEP 80730-300.

E-mails: janete.knapik@up.edu.br / janete.knapik@gmail.com

\section{Bruno Henrique Rocha Fernandes}

E-mail: rocha.fernandes@pucpr.br

\section{Synara Sepúlveda Sales}

E-mail: synarasepulveda@hotmail.com 